\title{
Nueva alternativa para el tratamiento para Covid 19 en Ecuador
}

Alexander Oswaldo Ojeda Crespo

Alexander Xavier Ojeda Cedillo ${ }^{2}$

Andrés Eduardo Ojeda Cedillo²

Peter Oswaldo Ojeda Cedillo²

Anaxímenes León ${ }^{3}$

\section{RESUMEN}

En Ecuador hay más de 4000 casos confirmados de coronavirus, y Guayaquil reporta el mayor número de contagiados y 450 muertos en todo el país. Y según los expertos médicos estiman que los fallecidos en los siguientes meses llegarán a entre 2500 y 3500 por covid 19 solo en la provincia del Guayas. La epidemia comenzó en Wuhan, China, y se extendió rápidamente por todo el país y posteriormente en todo el mundo. La OMS advierte que COVID-19 es el "enemigo público número 1 " y potencialmente más poderoso que el terrorismo por lo que declaro la pandemia. El objetivo de la presente investigación es determinar el beneficio de la utilización de claritromicina, N-acetilcisteina, Viusid y Té en los pacientes contagiados con COVID 19. Se administró el tratamiento a doce pacientes contagiados y sus contactos. Existen tratamientos utilizados en varios países del mundo con diferentes resultados, y, ante la situación gravísima del Ecuador, comparto mi experiencia personal con benéficos excelentes.

Palabras claves: COVID-19. Coronavirus. Pandemia. Tratamiento.

\section{SUMMARY}

In Ecuador there are more than 4,000 confirmed cases of coronavirus, and Guayaquil reports the highest number of infected and 450 deaths in the entire country. And according to medical experts estimate that those who died in the following months will reach between 2,500 and 3,500 due to covid 19 only in the province of Guayas. The epidemic began in Wuhan, China, and spread rapidly throughout the country and later throughout the world. The WHO warns that COVID-19 is the "public enemy number 1" and potentially more powerful than terrorism, which is why I declare the pandemic. The objective of the present investigation is to determine the benefit of the use of clarithromycin, $\mathrm{N}$-acetylcysteine, Viusid and Tea in patients infected with COVID 19. The treatment was administered to twelve infected patients and their contacts. There are treatments used in various countries of the world with different results, and, given the very serious situation in Ecuador, I share my personal experience with excellent benefits.

Keywords: COVID-19. Coronavirus. Pandemic treatment.

\section{INTRODUÇÃO}

Los CoV se han considerado tradicionalmente patógenos no letales para los humanos, principalmente causando aproximadamente el $15 \%$ de los resfriados comunes. Sin embargo, en este siglo, hemos encontrado CoV humanos altamente patógenos dos veces, es decir, SARS-COV y MERS-CoV, que causaron un brote originalmente en China en 2003 y Arabia Saudita en 2012, respectivamente, y pronto se extendieron a muchos otros países con horrible morbilidad y mortalidad. Por lo tanto, el COVID-19 actual es el tercer brote de CoV en la historia registrada de humanos.

Resumiendo, el inicio de esta pandemia que azota al mundo, tiene su origen en casos reportados de neumonía a partir de 31 de diciembre 2019 en Wuhan por la Comisión Nacional de Salud de China. Siete días después (7 de enero 2010) se lanzó la voz de alerta de la secuencia del CoV. El 15 de enero de 2020 se informó el primer caso fatal de Coronavirus en Wuhan. Mientras tanto, la epidemia se extendió rápidamente a las ciudades, provincias y países vecinos. El 20 de enero, se informó la infección de los proveedores de atención médica, lo que sugiere que la transmisión de persona a persona era posible. El 23 de enero, la ciudad de Wuhan fue bloqueada y todo su transporte público detenido. El 24 de enero, el primer estudio clínico sobre la enfermedad informó que, de 41 pacientes con casos

\footnotetext{
${ }^{1}$ Médico, Docente Investigador, Universidad Técnica de Machala, El Oro, Ecuador, aojeda@utmachala.edu.ec, http://orcid.org/0000-0003-2657-1736

2 Médico posgradista Universidad del Zulia, Maracaibo. Venezuela.

${ }^{3}$ Médico especialista Coordinador del Doctorado Universidad del Zulia, Maracaibo, Venezuela, anaxleon@gmail.com.

$\triangle \otimes \square \square \square$

Como citar este artigo / How to cite this article

Ojeda Crespo AO, Ojeda Cedillo AX, Ojeda Cedillo AE, Ojeda Cedillo PO, León A. Nueva alternativa para el tratamiento para Covid 19 en Ecuador. InterAm J Med Health 2020;3:e202003013.
} 
confirmados, solo 21 tenían contacto directo con el mercado de mariscos de Wuhan, que se consideraba el sitio de inicio de la infección de una fuente animal desconocida [1]. El 30 de enero, la OMS declaró el brote como una emergencia sanitaria mundial. Al momento de la redacción de este artículo, la enfermedad ya se ha extendido por toda China y la mayoría de los países de todo el mundo declarándola la OMS como una pandemia con miles de infectados y muertos. A medida que la situación evoluciona rápidamente, queda por determinar el alcance final y la gravedad del brote [2].

Los CoV son una subfamilia de virus grandes y envueltos que contienen una sola cadena de ARN sensorial. Se pueden dividir en cuatro géneros, es decir, alfa, beta, gamma y delta, de los cuales se sabe que los CoV alfa y beta infectan a los humanos. La glicoproteína del pico de la envoltura (S) se une a sus receptores celulares enzima convertidora de angiotensina 2 (ACE2) y dipeptidil peptidasa 4 (DPP4) para SARS-CoV y MERS$\mathrm{CoV}$, respectivamente, y luego se produce la fusión de la membrana. El genoma viral de ARN se libera en el citoplasma; Después de la replicación del genoma viral, el ARN genómico acompañado de glicoproteínas de envoltura y proteínas de nucleocápside forma vesículas que contienen viriones, que luego se fusionan con la membrana plasmática para liberar el virus [3].

Se ha demostrado que el SARS-CoV-2 infecta las células epiteliales respiratorias humanas a través de una interacción entre la proteína $S$ viral y el receptor de la enzima convertidora de angiotensina en células humanas; así, el SARS-CoV-2 posee una fuerte capacidad para infectar a los humanos [4].

\section{Tratamiento para el COVID 19}

Algunos países utilizan varios medicamentos para tratar el coronavirus. La Sociedad Española de Medicina, se hace eco en un documento de las recomendaciones del protocolo elaborado para tratar el Covid-19. El tratamiento antiviral específico contempla medicamentos como Lopinavir/ritonavir oral (se requiere consentimiento informado). Este medicamento está indicado para ayudar a controlar la infección del virus de la inmunodeficiencia humana $(\mathrm{VIH})$. Se tome solo por vía oral o en acompañamiento de un interferon beta1b. En este caso, se recomienda Betaferon, indicado para el tratamiento de la esclerosis múltiple. Los interferones son proteínas producidas por el organismo que le ayudan a combatir contra los ataques al sistema inmunitario, tales como las infecciones víricas $[5,6]$.

También se pude utilizar el Lopinavir/ritonavir combinado con un interferon alfa- 2B como Introna, que modifica la respuesta del sistema inmune del organismo para ayudar en la lucha frente a infecciones y enfermedades graves.

Otro tratamiento señalado es con Remdesivir. Este fármaco está indicado contra el ébola, y ya hay tres hospitales españoles llevando a cabo ensayos clínicos con este fármaco: Hospital La Paz, el Clínic de Barcelona y Cruces de Bilbao.

\section{Fármacos en fase de prueba o sin evidencia probada contra el SARS-CoV-2}

Aparte de los fármacos ya señalados, muchos países apuntan a que "se están utilizando otros medicamentos, con una evidencia muy limitada y fuera de ficha técnica, como son la hidroxicloroquina, cloroquina, azitromicina, amoxicilina ácido clavulanico,Nitazoxanida, darunavir/cobicistat y tocilizumab (biológico)". La hidroxicloroquina está indicada para tratar la artritis reumatoide, el lupus o ataques agudos de malaria, y, la cloroquina para paludismo o infecciones protozoarias o por helmintos $y$ la combinación darunavir/cobicistat para VIH [7].

En el caso del tocilizumab, indicado para la artritis reumatoide, pero algunas Escuelas Científicas Medicas, así como hospitales están llevando a cabo estudios probando este medicamento en pacientes con coronavirus que presentan valores de IL- 6 elevados y afirman que está dando "buenos resultados". Desgraciadamente los retrovirales, biológicos e interferón son inalcanzables para muchos Países en el mundo por su costo y sin una seguridad ciento por ciento de excelentes resultados.

\section{Claritromicina}

es un antibiótico macrólido, aprobado por la Administración de Alimentos y Medicamentos de los Estados Unidos (U.S. Food and Drug Administration, FDA) para tratar ciertas infecciones bacterianas, incluso la neumonía adquirida en la comunidad, la infección de la garganta (faringitis), las infecciones agudas de los senos paranasales y otras infecciones causadas por tipos específicos de bacterias. La claritromicina también está 
aprobada por la FDA para la prevención y el tratamiento de la infección por el complejo Mycobacterium avium (MAC), otra infección bacteriana.

La infección diseminada por el complejo MAC y ciertas enfermedades respiratorias bacterianas (como la neumonía adquirida en la comunidad) son infecciones oportunistas (IO) características de la infección por el VIH. Una 10 es una infección que ocurre con más frecuencia o es más grave en las personas con inmunodeficiencia como las que tienen el VIH - que en las personas con un sistema inmunitario sano [9].

Los efectos inmunomoduladores de los macrólidos se describieron por primera vez en pacientes con panbronquiolitis difusa en 1998. Se encontró que la inmunomodulación con macrólidos es independiente de las propiedades antibióticas. Sus efectos incluyen la modulación (tanto creciente como decreciente) de la producción de citocinas inflamatorias, disminuyendo la hipersecreción de moco de las vías respiratorias y bloqueando la formación de biopelículas bacterianas y la producción de factor de virulencia. La terapia con macrólidos se ha recomendado para la enfermedad pulmonar obstructiva crónica, fibrosis quística, bronquiectasias de fibrosis no quística y asma grave. En pacientes con asma, se informó que la terapia a largo plazo con macrólidos mejora el flujo de aire, la calidad de vida y la hipersensibilidad de las vías respiratorias [10].

La periostina es una proteína de matriz extracelular que está asociada con la inflamación de la vía aérea eosinofílica y la gravedad del asma. La periostina puede aumentar la inflamación tipo 2 y la hipersecreción de moco. Se informa que la periostina es el biomarcador más robusto que predice la efectividad del lebrikizumab, un anticuerpo anti-IL-13, para tratar el asma [11]. Como los macrólidos también afectan la inflamación dominada por el tipo 2 en el asma, planteamos la hipótesis de que la terapia con macrólidos puede atenuar la producción de periostina estimulada por IL-13 y la expresión de genes inflamatorios en fibroblastos de pulmón humano.

La claritromicina suprime la producción de periostina inducida por IL-13 en fibroblastos de pulmón humano, en parte a través de la inhibición de la fosforilación de STAT [12]. Esto sugiere un nuevo mecanismo del efecto inmunomodulador de la claritromicina en la inflamación y fibrosis de las vías respiratorias de los asmáticos y como sabemos es una enfermedad atopica.

\section{N-Acetilcisteina}

$\mathrm{N}$-acetilcisteína, un mucolítico que ha sido redescubierto como antioxidante gracias a la aparición de nuevos estudios, experimentales y clínicos, que apuntan unos beneficios añadidos.

Entre estas propiedades adicionales, que lo diferencian y separan del resto de mucolíticos, destaca sobre todo su capacidad antioxidante, que le permite contrarrestar el desequilibrio oxidativo que se descubre en el origen de enfermedades tan importantes como la EPOC, la fibrosis pulmonar o el infarto, así como en aquellas situaciones en las que se induce estrés oxidativo como la aplicación de contraste radiológico donde actúa como protector, evitando el daño renal. Además, posee un efecto antiinflamatorio y de remodelación de la estructura pulmonar [13].

El moco bronquial es producido por las células caliciformes, las células serosas y se almacena hasta que una señal de secreción es emitida. El exceso de moco favorece complicaciones en pacientes con COVID 19 y el estrés oxidativo juega un papel en la patogenia y progresión de las enfermedades pulmonares. Las especies reactivas $u$ oxiradicales causan cambios estructurales en los componentes esenciales de los pulmones, dando lugar a daños irreversibles tanto del parénquima como en las paredes de las vías respiratorias. A partir de evidencia in vitro e in vivo, se ha demostrado que la $\mathrm{N}$-acetilcisteína protege los pulmones contra los agentes tóxicos mediante el aumento de los mecanismos de defensa pulmonar a través de sus propiedades antioxidantes directas e indirectas al ser precursor de la síntesis de glutatión (GSH) un antioxidante importante en el pulmón con un efecto de protección contra agentes tóxicos internos y externos.

Algunos medicamentos como el parecetamol se ha demostrado que depleciona el Glutation S trasferasa del pulmón; colocando al paciente en desventaja contra el coronavirus que no podrá luchar contra la avalancha o tormenta de citocinas producido por el virus y la anorexia que reduce aún más la disponibilidad de uno de los más potentes antioxidantes que posee el organismo como es el glutatión, de ahí la importancia del uso de $\mathrm{N}$-acetilcisteina en estos pacientes.

Uno de los estudios en los últimos años en el 
ámbito de las enfermedades respiratorias, el BRONCUS (Bronchitis Randomised On Nac Cost-Utility Study), ha corroborado la capacidad de la N-acetilcisteína (NAC) para prevenir el desarrollo de reagudizaciones de la enfermedad pulmonar obstructiva crónica. Los resultados de este macro ensayo, con 3 años de seguimiento, llevado a cabo en 10 países europeos, fueron presentados en durante el Congreso de la Sociedad Europea de Respiratorio, celebrado el 2011 en Viena [14].

\section{VIUSID}

Viusid es un suplemento nutricional con propiedades antioxidantes e inmunomoduladoras reconocidas que tienen efectos beneficiosos sobre los resultados clínicos relacionados con la cirrosis, como la supervivencia, la progresión de la enfermedad y el desarrollo de carcinoma hepatocelular (CHC). Este estudio evaluó la eficacia y seguridad de viusid en pacientes con cirrosis descompensada relacionada con el VHC [15].

Viusid (laboratorio Catalyis, Madrid, España) es un suplemento nutricional que contiene diferentes moléculas (ácido ascórbico, zinc y ácido glicirrícico) con reconocidas propiedades antioxidantes e inmunomoduladoras. Se sabe que la glicirricina $(0,033$ g), el ingrediente activo más importante del suplemento, tiene un efecto inmunomodulador, antiviral y biológica. A Demostrado diferentes propiedades antiinflamatorias (aumento de la producción de interleucina 10 (es una potente citocina antiinflamatoria que inhibe la síntesis de muchas proteínas proinflamatorias)), un efecto antiapoptótico, la proliferación de hepatocitos y la estabilización de las membranas celulares hepáticas.

Datos recientes sugieren que viusid mejora el estrés oxidativo a través de la reducción de los productos de peroxidación lipídica y tiene un efecto inmunomodulador sobre la secreción de citocinas a través de una mayor producción de IFN- $₫$ e interleucina (IL) -10, disminución de la producción de IL-1囚 y factor de necrosis tumoral estabilizado $\nabla$ secreción en pacientes con VHC que han fallado en el tratamiento antiviral previo [16].

\section{Té}

El té se consume ampliamente en todo el os mundo. En general, el té se divide en seis categorías: tés blanco, verde, amarillo, oolong, negro y oscuro, según el grado de fermentación. El té contiene abundantes fitoquímicos, como polifenoles, pigmentos, polisacáridos, alcaloides, aminoácidos libres y saponinas [17]. Beber té es seguro para los humanos, ya que los informes sobre los graves efectos adversos del consumo de té son raros.

Además, muchos estudios han indicado que el té y sus componentes bioactivos poseen múltiples funciones de salud, que incluyen antioxidación, antiinflamación, inmunorregulación, anticancerígeno, protección cardiovascular, antidiabética, antiobesidad, y hepatoprotección [18]. Además, se han adoptado varias tecnologías, incluida la nanotecnología desarrollada recientemente, para mejorar la biodisponibilidad de los polifenoles del té. Además, los efectos adversos del té rara vez se observaron. Por lo tanto, la combinación de funciones de salud y seguridad del té respalda su consumo para personas con el potencial de prevenir y controlar ciertas enfermedades agudas y crónicas, como respiratorias, digestivas, la obesidad y el cáncer [19]

Las saponinas son otro componente bioactivo en la elaboración de té y su extracto, y generalmente exhiben efectos antioxidantes, inmunorreguladores, anticancerígenos y protectores cardiovasculares. Además, las saponinas de té generalmente se consideran compuestos seguros que tienen propiedades antifúngicas e insecticidas y se usan ampliamente en el campo de la agricultura y la industria alimentaria [20].

\section{Metodología}

Doce pacientes confirmados por COVID-19 manejados ambulatoriamente en sus domicilios desde $16 \mathrm{de}$ marzo al 2 de abril 2020 en la ciudad de Machala Provincia de El Oro y a dos horas y media de la Provincia del Guayas (que reporta el mayor número de contagiados y fallecidos). Entre estos se encontraban cuatro médicos, dos enfermeras y seis pacientes particulares en edades comprendidas entre 35 a 65 años de edad y todos residentes en la misma ciudad. Los seis primeros por contagio hospitalario y los seis restantes por contagio comunitario.

Dentro de la signo y sintomatología, la mayoría solo presentaban dolores musculares, cefalea y febrícula, hiporexia. Un médico y una enfermera presentaron tos con expectoración blanquecina amarillenta y saturación de $90 \%$ por lo que requirieron ingreso por 8 horas en 
una unidad hospitalaria y regresando posteriormente a su cuarentena domiciliaria

La información registrada incluye datos demográficos, historial médico, historial de contacto, potencial comorbilidades, síntomas, signos, resultados de pruebas de laboratorio, radiografía de tórax y tratamiento de 10 días a base de viusid tres sobres diarios, claritromicina $500 \mathrm{mg}$ cada 12 horas, acetilcisteina $600 \mathrm{mg}$ diarios y acetominofen 1 gramo cada 8 horas y complementado con té caliente 4 veces al día, todos por vía oral

A los contactos de los pacientes además del aislamiento se les administro 1 sobre diario de viusid y claritomicina 500mg por 10 dias. Té caliente 3 veces al día y $\mathrm{N}$-acelticisteina por razones necesarias

\section{RESULTADOS}

Dos pacientes (médico y enfermera) presentaron compromiso respiratorio con tos y disminución de la saturación de oxigeno $90 \%$ y que requirieron ingreso por 8 horas a una unidad hospitalaria. En la Radiografía de tórax de encontró patrón intersticial con pequeña consolidación en base pulmonar derecha en el medico e infiltrados bilaterales en la enfermera. Al encontrarse dañado el tomógrafo no se pudo realizar este procedimiento.

Al realizarles el control y seguimiento por parte de los funcionarios del ministerio de salud se estableció la mejoría de los mismos en un 95\% hasta la realización del presente artículo y la prueba para coronavirus se la realizarán en 15 días. Sin embargo, se mantendrán en aislamiento domiciliario.

Todos los contactos directos e indirectos de los pacientes contagiados evolucionaron satisfactoriamente sin complicación alguna

\section{DISCUSIÓN}

El uso de claritromicina, $\mathrm{N}$-acetilcisteina, viusid y Té demostró una efectividad en los pacientes antes mencionados basados en la evidencia científica de los beneficios de cada uno de sus componentes y además por ser muy seguros, se puede utilizar a cualquier edad de acuerdo a las dosificaciones farmacológicas establecidas. La medicina es basada en evidencia y seguramente se harán observaciones que serán bienvenidas, pero los invito a utilizar lo antes mencionado como una nueva alternativa de tratamiento ante esta pandemia que está aniquilando la humanidad

\section{Protección de personas y animales.}

Los autores declaran que para esta investigación no se han realizado experimentos en seres humanos ni en animales.

\section{Confidencialidad de los datos.}

Los autores declaran que en este artículo no aparecen datos de pacientes. Derecho a la privacidad y consentimiento informado.

\section{Financiación}

El presente trabajo fue financiado en su totalidad por los autores. Conflicto de intereses Los autores declaran no tener ningún conflicto de intereses.

\section{BIBLIOGRAFIA}

1. Ye Yi, Philip N.P. Lagniton, Sen Ye, Enqin Li and Ren-He Xu. COVID-19: what has been learned and to be learned about the novel coronavirus disease [Internet]. ljbs.com. 2020 [cited 3 April 2020]. Available from: http://www.ijbs.com/v16p1753.htm

2. Velavan TP, Meyer CG. La epidemia de COVID-19. Trop Med Int Health. 2020. DOI: https://doi.org/10.1111/tmi.13383.

3. La OMS advierte que el coronavirus, ahora denominado COVID-19, es el "enemigo público número 1 " y potencialmente más poderoso que el terrorismo. https://www.abc.net.au/ news/2020-02-12/coronavirus-public-enemy-number-onevaccine/11956446

4. Zhang YZ. Novela 2019 genoma de coronavirus. http://virological. org/t/novel-2019-coronavirus-genome/319

5. Paules $\mathrm{Cl}$, Marston HD, Fauci AS. Infecciones por coronavirus: más que solo el resfriado común. JAMA 2020 Doi: 10.1001 / jama.2020.0757

6. Wang C, Horby PW, Hayden FG, Gao GF. Un nuevo brote de coronavirus de preocupación mundial para la salud. Lanceta. 2020; 395:470-473.

7. CDC: 2019 Novela Coronavirus, Wuhan, China. https://www.cdc gov/coronavirus/2019-ncov/index.html

8. Komiya K, Ohta S, Arima K, Ogawa M, Suzuki S, Mitamura Y et al. Clarithromycin attenuates IL-13-induced periostin production in human lung fibroblasts. 2020.

9. McCarty JM. Clarithromycin in the management of communityacquired pneumonia. Clin Ther. 2000;22:281-94.

10. Tanabe T, Kanoh S, Tsushima K, Yamazaki Y, Kubo K, Rubin BK. Clarithromycin inhibits interleukin-13-induced goblet cell 
hyperplasia in human airway cells. Am J Respir Cell Mol Biol. 2011;45:1075-83.

11. Shoda T, Futamura K, Kobayashi F, Saito H, Matsumoto K, Matsuda A. Cell type-dependent effects of corticosteroid on periostin production by primary human tissue cells. Allergy. 2013;68:1467-70.

12. Kanoh S, Rubin BK. Mechanisms of action and clinical application of macrolides as immunomodulatory medications. Clin Microbiol Rev. 2010; 23:590-615.

13. Poole P, Sathananthan K, Fortescue R. Mucolytic agents versus placebo for chronic bronchitis or chronic obstructive pulmonary disease. Cochrane Database of Systematic Reviews 2019, Issue 5. Art. No.: CD001287. doi: 10.1002/14651858.CD001287. pub6

14. Melo, A. Moco de vías respiratorias y N-acetilcisteína. (2018, Enero 13).[cited 3 April 2020].Available from: https://www. researchgate.net/publication/212635550

15. Eduardo Vilar Gomez, Yadina Martinez Perez, Hector Vega Sanchez, Gretel Riveron Forment. Antioxidant and Immunomodulator Properties of Viusid in Patients With Chronic Hepatitis C - Full Text View - ClinicalTrials.gov [Internet]. Clinicaltrials.gov. 2020 [cited 3 April 2020]. Available from: https://clinicaltrials.gov/ct2/ show/NCT00778843

16. Vilar Gomez E, Sanchez Rodriguez Y, Torres Gonzalez A, Calzadilla Bertot L, Arus Soler E, Martinez Perez Y et al. Viusid, a nutritional supplement, increases survival and reduces disease progression in HCV-related decompensated cirrhosis: a randomised and controlled trial. 2020.

17. Tang G, Meng X, Gan R, Zhao C, Liu Q, Feng $Y$ et al. Health Functions and Related Molecular Mechanisms of Tea Components: An Update Review. 2020.

18. Guo, YJ, Sun LQ, Yu BY, Qi J. An integrated antioxidant activity fingerprint for commercial teas based on their capacities to scavenge reactive oxygen species. Food Chem. 2017;237:645653.

19. Farooq, S.; Sehgal, A. Efect of consecutive steeping on antioxidant potential of green, oolong and black tea. Int J Food Sci Technol. 2018;53:182-187.

20. Kujawska M, Ewertowska M, Ignatowicz E, Adamska T, Szaefer $\mathrm{H}$, Gramza-Michalowska A, et al. Evaluation of safety and antioxidant activity of yellow tea (Camellia sinensis) extract for application in food. J Med Food. 2016;19:330-336.

21. Raj VS, Mou H, Smits SL, Dekkers DH, Muller MA, Dijkman R, et al. La dipeptidil peptidasa 4 es un receptor funcional para el emergente coronavirus-EMC humano. Naturaleza. 2013; 495:251-4.

22. Zhou $P$, Yang $X L$, Wang $X G$, Hu $B$, Zhang $L$, Zhang $W$, et al. 2020. Descubrimiento de un nuevo coronavirus asociado con el reciente brote de neumonía en humanos y su posible origen de murciélagos. bioRxiv. Doi: 10.1101 / 2020.01.22.914952. 